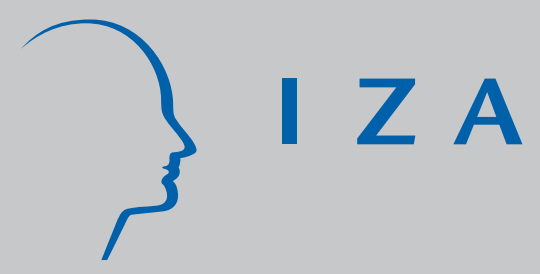

IZA DP No. 3833

Underpaid or Overpaid? Wage Analysis for Nurses Using J ob and Worker Attributes

Barry T. Hirsch

Edward J. Schumacher

November 2008 


\title{
Underpaid or Overpaid? Wage Analysis for Nurses Using Job and Worker Attributes
}

\author{
Barry T. Hirsch \\ Georgia State University \\ and IZA
}

\author{
Edward J. Schumacher \\ Trinity University
}

Discussion Paper No. 3833

November 2008

\author{
IZA \\ P.O. Box 7240 \\ 53072 Bonn \\ Germany \\ Phone: +49-228-3894-0 \\ Fax: +49-228-3894-180 \\ E-mail: iza@iza.org
}

\begin{abstract}
Any opinions expressed here are those of the author(s) and not those of IZA. Research published in this series may include views on policy, but the institute itself takes no institutional policy positions.

The Institute for the Study of Labor (IZA) in Bonn is a local and virtual international research center and a place of communication between science, politics and business. IZA is an independent nonprofit organization supported by Deutsche Post World Net. The center is associated with the University of Bonn and offers a stimulating research environment through its international network, workshops and conferences, data service, project support, research visits and doctoral program. IZA engages in (i) original and internationally competitive research in all fields of labor economics, (ii) development of policy concepts, and (iii) dissemination of research results and concepts to the interested public.
\end{abstract}

IZA Discussion Papers often represent preliminary work and are circulated to encourage discussion. Citation of such a paper should account for its provisional character. A revised version may be available directly from the author. 
IZA Discussion Paper No. 3833

November 2008

\section{ABSTRACT \\ Underpaid or Overpaid? Wage Analysis for Nurses Using Job and Worker Attributes ${ }^{\star}$}

The nursing labor market presents an apparent puzzle. Hospitals report chronic shortages, yet standard wage analysis shows that nursing wages have increased over time and greatly exceed those received by other college-educated women. This paper addresses this puzzle. Data from the Current Population Survey (CPS) are matched with detailed job content descriptors from the Occupational Information Network (O*NET). Nursing jobs require higher levels of skills and more difficult working conditions than do jobs for other college educated workers. A standard CPS-only wage regression shows a registered nurse (RN) wage advantage of .22 log points compared to a pooled male/female group of college-educated workers. Control for $\mathrm{O}^{\star} \mathrm{NET}$ job attributes reduces the RN gap to .08, while an arguably preferable nonparametric estimator produces a wage gap estimate close to zero. We conclude that nurses receive compensation close to long-run opportunity costs, narrowing if not resolving the RN wage-shortage puzzle.

JEL Classification: I12, J31, J44

Keywords: nursing, wage differentials, job attributes

Corresponding author:

Barry T. Hirsch

Department of Economics

Andrew Young School of Policy Studies

Georgia State University

Atlanta, Georgia 30302-3992

USA

E-mail: bhirsch@gsu.edu

\footnotetext{
* We appreciate research assistance from Erin Coffman, plus comments from Joanne Spetz and seminar participants at UNC Charlotte and at the "Nursing Work Force" session, American Society of Health Economists (ASHE) meetings, Durham, NC, June 2008.
} 


\section{Introduction}

The labor market for registered nurses (RNs) presents an apparent puzzle. Nurses are widely believed to be in short supply, with hospitals reporting unfilled vacancies over sustained periods and shortfalls in future supplies of nurses widely predicted. ${ }^{1}$ Sustained shortages of RNs are seemingly inconsistent with a theory of competitive markets wherein wages tend toward levels equating labor demand and supply. ${ }^{2}$ Sustained shortages can exist in monopsonistic labor markets, yet evidence supporting nursing monopsony is neither abundant nor compelling (e.g., Hirsch and Schumacher 2005; Matsudaira 2008). Moreover, wage analyses indicate that RN relative wages have increased markedly over time and are well in excess of wages received by other college-educated women. In short, an argument can be made that RNs are on average "underpaid” based on evidence of shortages. And an argument can be made that RNs are "overpaid” based on wage analyses. It is unlikely that both views are correct.

In this study we address the nursing wage-employment puzzle and attempt to answer the question in the title: Are registered nurses paid wages well below, well above, or close to long-run opportunity costs? We examine a large dataset containing information on individual RN and non-RN wages and attributes. These data are supplemented by a newly developed database providing a rich set of job content descriptors measuring occupational skills and working conditions. Standard wage equation analysis from the Current Population Survey (CPS) suggests a substantial wage premium for RNs relative to other college-educated women, following controls for worker and location characteristics. Detailed job content descriptors from the Occupation Information Network $\left(\mathrm{O}^{*} \mathrm{NET}\right)$ provide evidence that nursing jobs involve relatively high levels of skill and demanding working conditions. Incorporating the O*NET measures of job content into the CPS analysis, coupled with an expansion of the comparison group to include male as well as female workers, sharply reduces estimates of relative RN wages. Use of a nonparametric rather than standard Mincerian semilog regression approach reduces estimates of the RN differential further, suggesting that RNs are paid wages close to long-run opportunity costs. We find little evidence that nursing wages fall below opportunity costs, at least not to any substantial degree.

Our analysis does not fully "solve” the RN shortage puzzle stated at the outset, but does sharply reduce its dimensions. We conclude that nurses receive wages close to opportunity costs. We suggest (but do not provide direct evidence) that increasing demand for RNs combined with barriers and sluggish

\footnotetext{
${ }^{1}$ See National Center for Health Workforce Analysis (2002); Spetz and Given (2003), and Aiken (2008).

2 Our focus is on "economic" shortages, which exist when there is excess demand at the current wage level or, in a dynamic setting, labor demand is increasing faster than supply and wages are slow to adjust. The nursing human resource literature often focuses on "need-based" shortages, which can be defined to exist when the available number of workers is less than the number analysts regard as necessary to serve a given market. See Folland, Goodman, and Stano (2007, pp 338-344).
} 
growth in RN training can produce both periodic nursing shortages and wages moderately higher than long-run opportunity costs.

Apart from addressing the wage-employment puzzle among registered nurses, an implication of the paper is that wage and job analyses in health (and non-health) labor markets are enriched through the consideration of job content measures of skill and working conditions. In what follows we first review theory and evidence on nursing wages and employment. We then discuss construction of the matched CPS/O*NET database and provide evidence on how RNs compare to other college-educated workers in wages, required job skills, and working conditions.

\section{Theory and evidence on nursing labor markets}

Competitive labor markets have multiple employers, minimal entry barriers among workers and firms, worker mobility across employers, and good information among workers and employers regarding employment and wage opportunities. Such markets should produce wages roughly the same among similarly skilled workers with similar preferences who perform similar levels of work (i.e., skills and working conditions), the so-called "law of one wage."

Of course, there is not literally a common wage for identical workers in identical jobs. Even in highly competitive markets, idiosyncratic factors (often unmeasuable) among workers, jobs, and locations generate equilibrium wage differences. ${ }^{3}$ Factors shifting labor demand and supply change continually, so wages move toward but do not mechanically achieve levels that equilibrate demand and supply. Yet if wages are approximately competitive, we do not expect to see a sustained shortage (unfilled vacancies) or sustained surplus of qualified but unemployed applicants.

Because high vacancy levels in nursing positions are common, a natural explanation for economists to consider is monopsonistic power among employers, particularly in hospitals where a (declining) majority of RNs are employed. The canonical competitive model views employers such as hospitals being “price (wage) takers” - hospitals face a perfectly elastic firm-level nursing supply curve. The pure monopsony model assumes a labor market with a single employer, for example a hospital that is the sole employer of RNs with no mobility across occupations or labor markets. The graphical monopsony model, standard in economics textbooks, is shown in a Figure 1. The monopsonist maximizes profits by equating its marginal revenue product (measured by $\mathrm{D}_{\mathrm{L}}$ ) and marginal labor costs (MLC) at the belowcompetitive wage $\mathrm{W}_{2}$ and employment $\mathrm{E}_{2}$. The hospital prefers to hire $\mathrm{E}_{3}$ nurses at $\mathrm{W}_{2}$, but only $\mathrm{E}_{2}$ are

\footnotetext{
${ }^{3}$ Factors that break down equivalency between wages and spot productivity include training and skills that are firmspecific (i.e., non-transferable), compensation tied to company seniority (independent of skills), defined benefit pension plans that highly penalizes quits among young workers, earnings linked to group rather than individual productivity, and pay based on time input rather than hard to measure output. Moreover, competitive wages differ across geographic labor markets due to differences in area amenities and disamenities (weather, water, crime, etc.), prices, productivity (e.g., agglomeration economies), and state and local fiscal policies (public goods and taxes).
} 
available at that wage. The hospital could raise wages to attract more employees, but that would lower profits. Hence, pure monopsony is characterized by a systematic labor shortage $\left(E_{3}-E_{2}\right)$.

Real world nursing markets do not satisfy the assumptions of either pure competition or monopsony. Even in small markets with few nursing employers, RNs have some ability to move between employers and across labor markets. Even in large markets with hundreds of hospital and non-hospital nursing employers, employers do not literally face a horizontal labor supply curve. Were they to lower wages they would not lose all their nurses; were they to raise nursing wages they would increases the number of qualified job applicants but not infinitely so. For the real world case where each nursing employer faces an upward-sloping labor supply curve but there exist multiple employers, economic theory alone (i.e., without empirical evidence) does not point unambiguously to a specific wageemployment outcome. Most economists believe that labor markets typically have numerous buyers and sellers and sufficient mobility to produce roughly competitive outcomes. But there is not agreement over just how "rough" is roughly competitive.

"New monopsony” models focus on worker mobility and the information available to workers on alternative employment opportunities (Bhaskar, Manning, and To 2002; Manning 2003). Rather than focusing on the number of employers in a geographic area, this literature argues that imperfect information, firm-specific training, worker-specific attachment to firms, and immobility arising from various sources, employers face upward sloping labor supply. Profit maximizing employment and wages will vary with the elasticity of labor supply.

What is the evidence on monopsonistic power in nursing? There exist two distinct strands of literature. One focuses on obtaining estimates of the labor supply curve elasticity facing employers, with monpsonistic power argued to be a function of the inverse elasticity (e.g., see papers summarized in Boal and Ransom 1997). The difficulty here is in obtaining evidence on firm (e.g., hospital) rather than market labor supply, since it is the former that is relevant in the monopsony model. Although there are not a large number of studies here, earlier studies suggest non-zero inverse elasticities, implying upward sloping labor supply curves (Sullivan 1989; Staiger et al. 1999). A recent study by Matsudaira (2008), which arguably is the best among these studies at identifying RN labor supply to the firm, finds little evidence of upward sloping labor supply in California nursing homes.

The second strand of literature does not estimate labor supply elasticities but instead examines whether one sees wage and employment outcomes consistent with monopsony. For example, Hirsch and Schumacher (2005) examine wage differences in RNs across U.S. labor markets. ${ }^{4}$ They use as their outcome measure the wage of RNs in each market relative to a comparison group of workers outside the

\footnotetext{
${ }^{4}$ Another recent example is Currie, Farsi, and MacLeod (2005), who examine adjustments in nurses' required effort in addition to wages and employment.
} 
health sector, conditioning on schooling, experience, and numerous demographic characteristics. They find that RNs earn higher wages overall, but no cross-sectional evidence that relative nursing wages increase with city size and the number of hospital employers, or decrease with hospital concentration, as predicted by the monopsony model. Nor do they find employment patterns consistent with monopsony. They also include a test of "new monopsony" models that focus on worker mobility rather than market structure. Relative wages are not found to be related to an intercity measure of RN mobility across employers. Indeed, RNs exhibit high rather than low mobility as compared to the average worker. One piece of evidence consistent with the monopsony model is that relative nursing wage growth has been slower in markets where hospital concentration increased. The authors interpret the evidence as indicating short-run employer power that fades over time.

Thus, an apparent puzzle remains. Monopsony does not provide a convincing explanation for observed labor shortages and job vacancies in nursing labor markets. Not only is there little direct evidence, wage studies find that RNs earn not less but considerably more than similar non-RN employees (e.g., Hirsch and Schumacher 2005). If RNs realize sizable wage premiums, shortages are all the more puzzling? The focus of this paper is to reexamine the evidence on relative nursing wages. Does a nursing wage premium (or penalty) exist and, if so, how large is its magnitude? In short, is there a puzzle in need of explanation?

\section{Data description: The Current Population Survey}

Data on individual workers used in the wage analysis are from the Current Population Survey (CPS) Outgoing Rotation Group (ORG) monthly earnings files for January 2005 through June 2008. The CPS-ORG files include the quarter sample of households for whom the earnings supplement is administered. Our sample includes all employed non-student full-time wage and salary workers who are age 20 and over, report their earnings (i.e. imputed earnings are excluded), and have an associate degree (academic or vocational), a BA, or an MA. ${ }^{5}$

Our wage is a measure of usual average earnings per hour on one's primary job. The straight-time wage is reported directly in the CPS for hourly workers, including most RNs. This is used as our wage measure for workers without usual tips, overtime, or commissions. For salaried workers, plus hourly workers receiving supplemental pay, the wage is calculated as usual weekly earnings (inclusive of tips, overtime, and commissions) divided by usual hours worked per week. For the few such workers reporting variable usual hours, hours worked the previous week is used to calculate hourly earnings. For workers whose weekly earnings are top-coded (at \$2,885), mean earnings above the cap are assigned

\footnotetext{
${ }^{5}$ Part-time workers (defined as less than 35 usual hours worked per week on their principal job) are excluded from the comparison group sample, but not the RN sample. Wage differences between full-time and part-time RNs are very small. Results with part-time RNs excluded produce results nearly identical to those presented.
} 
based on gender-specific estimates assuming a Pareto distribution in the upper tail. ${ }^{6}$ All earnings figures are stated in January 2008 dollars. To reduce noise due to recording or reporting errors, a small number of observations with extreme implicit wage values (less than \$3 and \$150 or greater) are excluded.

As seen in table 1, the average hourly wage for RNs during 2005 through June 2008 is $\$ 29.45$, $7.4 \%$ more than the $\$ 27.43$ average for the college control group. ${ }^{7}$ Focusing instead on the difference in the mean log wage, the RN wage advantage is .178 log points (19.5\%), more than double the gap based on arithmetic means. ${ }^{8}$ The difference reflects a compressed RN (occupation-specific) wage distribution as compared to the control group's longer right tail. The standard deviation associated with RN wages is 11.6 versus 19.4 for the comparison group wage. Figure 2a shows the entire RN and control group distributions. As compared to the economy-wide college control group, the RN wage distribution lies to the right (ignoring the upper tail) and is substantially more compressed. Figure 2b shows the right tails of the distributions, restricting the sample to those with wages of at least \$45 in January 2008 dollars. Whereas there are virtually no RNs earning, over, say, \$80 an hour, there are nontrivial numbers of nonRNs realizing such earnings. These different distributions suggest that a nonparametric estimator may be in order (Blackburn 2007), an approach we explore later in the paper.

Excluded from the analysis are workers who do not report their earnings and thus have their hourly wage and/or usual weekly earnings imputed, $28.0 \%$ of the RNs and $28.7 \%$ of the control group sample. Such exclusion is important since nonresponding nurses (and other workers) are generally assigned earnings of workers in other occupations (broad occupation category is a donor match criteria). Inclusion of imputed workers causes a substantial attenuation in wage gap estimates (Hirsch and Schumacher 2004; Bollinger and Hirsch 2006). The final sample size, following the above exclusions, is 143,885, which includes 8,292 RNs and 135,593 employees in the college comparison group.

Means for the full sample including imputed earners are shown in the bottom portion of table 1. The impact of excluding imputed values is readily evident. As expected, mean wages for the broad control group are similar for the two samples (\$27.43 excluding and \$27.37 including imputations). But inclusion of imputed earners sharply reduces mean earnings for RNs, from $\$ 29.45$ absent imputations to \$28.21 with imputations (mean log wages decline .069 log points), since most nonresponding RNs are assigned the earnings of a non-RN donor. Effectively, the difference between the mean wage (or log wage) for responding RNs and the mean of the assigned wage among nonresponding RNs provides a

\footnotetext{
${ }^{6}$ Estimated mean earnings are about 1.6 times the cap for women and 1.8 for men. These estimates are calculated by Barry Hirsch and David Macpherson and posted at http://www.unionstats.com.

${ }^{7}$ Because the CPS, absent weighting, is not a representative sample, all means are calculated using CPS sample weights.

${ }^{8}$ As is common, percentage approximations are calculated using $100[\exp (\beta)-1]$, where $\beta$ is the coefficient on the RN dummy. As noted by Kennedy (1981), a more precise (but still biased) estimate would account for the variance of the estimate. For estimates presented in this paper, the Kennedy adjustment would typically reduce percentage gaps by a tenth of one percent.
} 
“matching” estimate of the RN wage advantage, conditioned on the Census hot deck match attributes (Bollinger and Hirsch 2006, table 1). ${ }^{9}$ RNs reporting their wage display a $16.4 \%$ percentage wage advantage (and a .230 log wage advantage) over the $\$ 25.30$ mean of the imputed wage (or 3.085 mean of imputed log wage) for nonrespondent RNs.

The importance of gender can be seen by breaking out average male and female wages of the control group. The average RN wage of \$29.45 is well above the \$23.18 mean wage for college women, but below the $\$ 31.11$ average for college men. Using log points, the RN unadjusted wage advantage is .306 relative to women and .060 relative to men.

\section{Skill and working condition indices constructed from the Occupational Information Network}

The Occupational Information Network (O*NET), produced by the U.S. Department of Labor's Employment and Training Administration, is a comprehensive database system for collecting, organizing, and describing data on job characteristics and worker attributes within occupations. The O*NET database has been created and updated over the past decade based on input from job analysts and job incumbents. The first public release version of O*NET was in late 1998. We use O*NET 12.0, released in June 2007.

A data set with 259 O*NET job descriptors from an initial 488 descriptors in the O*NET database was created. ${ }^{10}$ The job descriptors cover a wide range of attributes, including abilities that influence the acquisition and application of knowledge in problem solving to psychomotor, physical and sensory abilities to social, technical, and complex problem solving skills. Most O*NET variables involve types of job skills or attributes that are required of workers and are necessary to perform the tasks of an occupation. We construct two sets of indices from the O*NET database, our preferred approach based on factor analysis using 206 of the 259 O*NET attributes and a second based on additive indices of a subset of the 206 attributes. $^{11}$

To examine how pay varies with job attributes, we merge the O*NET database of job descriptors with the CPS database of individuals. Both O*NET and the CPS identify detailed occupations using Standard Occupational Classification (SOC) codes. The CPS identifies workers in 502 SOC civilian occupational categories, whereas O*NET provides a more detailed SOC breakdown, with 798 civilian

\footnotetext{
${ }^{9}$ Two caveats attach to this statement. First, some RNs will be assigned the earnings of an "identical" RN rather than non-RN donor, causing attenuation in the estimated gap. Second, it assumes "conditional missing at random" (Bollinger and Hirsch 2006); that is, response bias is ignorable once conditioning on the measured variables. Note that this Census "matching" estimator is conditioned on gender since sex is a Census hot deck match attribute.

${ }^{10}$ The CPS-O*NET database was created jointly by one of the authors and economists at Global Insight. Most O*NET job descriptors are measured using an "importance" and a "level" scale, with these values being very highly correlated. Descriptors measured in level form were retained and the "duplicative" descriptors eliminated, reducing the number of O*NET descriptors from an initial total of 488 to 259 with little loss in information. A small number of mostly small occupations had not yet released revised ratings since the initial version of O*NET.

${ }^{11}$ The reduction from 259 to 206 attributes is explained in Section 4 below.
} 
occupations. For the most part the crosswalk between O*NET and the CPS occupations is straightforward. $^{12}$

The merged CPS-O*NET database allows us to address an important question. Is a CPS-only analysis likely to understate or overstate the nursing/non-nurse wage differential? CPS variables account for individual worker characteristics, but do not fully account for job-specific skills and working conditions. Combining O*NET with the CPS allows us to account more directly for occupational skill requirements, working conditions, and other job attributes that influence wages. Because individual skills are measured imperfectly by the schooling and potential experience variables in the CPS, accounting for occupational job tasks also helps control for worker-specific skills. ${ }^{13}$

There is no unique method for collapsing the large number of O*NET occupational descriptors into a small number of informative variables. We opt for a relatively simple approach, creating single measures of a skill index (SK) and of a working conditions (WC) index. For the indices constructed using factor analysis, 206 of the total 259 O*NET variables in our database are used. Excluded were 26 "physical ability" attributes (e.g., finger dexterity, gross body coordination, and near vision) that can be considered neither workplace disamenities nor scarce compensable skills; 6 worker "Interest” attributes (investigative, social, realistic, etc.); and a set of 21 "Values" attributes (how well does this occupation satisfy needs for ability utilization, compensation, helping others, etc.) intended to help guidance counselors direct young people into selected fields. Of the remaining $206 \mathrm{O}$ *NET descriptors, the factor skill index, SK1, is constructed from 168 job attributes and the working condition index, WC1, from 38 attributes.

Using factor analysis, we construct a first principal factor SK1 that is a linear combination of the 168 skill attributes and a first principal factor WC1 that is a combination of the 38 working condition attributes. Each of the single first factors loads all attributes in a way that accounts for a maximum proportion of the covariance across attributes and occupations. The factor analysis is weighted by

\footnotetext{
${ }^{12}$ There is a one-to-one match from $\mathrm{O}^{*} \mathrm{NET}$ to the CPS for 316 occupations. Most of the remaining involve a mapping of two or more $\mathrm{O} * \mathrm{NET}$ occupations to a CPS category. In these cases, O*NET descriptor values are calculated based on the weighted average across the component O*NET occupations, using May 2005 employment reported in the Occupational Employment Statistics (OES) as weights. A small number of CPS occupational categories are made up of a combination of O*NET categories defined at such a fine level of detail that OES employment figures are not available. In these cases, component $\mathrm{O}$ NET occupations are assigned equal weights. Finally, a small number of CPS occupations are identified as "all other" categories (e.g., "information and records clerks, other") for which there are no O*NET ratings. These CPS occupation codes were assigned O*NET values based on an average ratings (using employment weights) among similar occupations.

${ }^{13}$ Ingram and Neumann (2006) discuss advantages of using job (occupation) attributes in addition to or instead of individual attributes in order to measure the returns to skill. Their paper also provides a careful discussion of factor analysis, which they use to create skill indices from the Dictionary of Occupational Titles (DOT).
} 
occupational employment, compiled from the CPS for all wage and salary workers. By construction, the factors have a mean of zero and standard deviation of 1.0. ${ }^{14}$

Note that SK1 and WC1 are constructed independently of the CPS wage data. In short, the factor analysis constructs single index values for each occupation that reflects a "principled” collapsing of all O*NET skill-related attributes and all the working condition attributes. ${ }^{15}$

Skill factor SK1 accounts for $41 \%$ of the total covariance among the 168 skill attributes across the 501 Census occupations. SK1 heavily loads such O*NET measures as critical thinking, judgment and decision making, monitoring, written expression, speaking, writing, active listening, written comprehension, active learning, negotiation, and persuasion.

The factor index WC1 accounts for 56\% of the total covariance among the 38 working condition attributes. WC1 heavily loads job attributes such as dynamic and static strength, very hot and cold temperatures, extremely bright or inadequate lighting, exposed to contaminants, cramped work space or awkward position, exposure to burns, cuts, bites, or stings, and exposure to hazardous equipment.

Our second method for constructing the skill and working condition indices is to take the simple arithmetic average of the O*NET attributes. ${ }^{16}$ The additive indices SK2 and WC2 use a subset of 154 of the 206 O*NET attributes used above, excluding variables for which theory does not a priori predict the sign. Skill index SK2 includes 135 of the 168 attributes used previously, excluding 33 "knowledge content” variables covering 33 subject areas (e.g., chemistry, design, fine arts, geography, etc.).

The working conditions index WC2 includes 19 of the previous 38 variables, excluding 2 "indoors" variable largely collinear with three outdoors variables; 9 variables measuring “time spent” in physical activities such as sitting, standing, using hands, etc.; 5 strength variables; and 3 work context variables measuring the conflict situations and dealing with unpleasant or physically aggressive people. The remaining attributes (seen subsequently in table 4) correspond closely to the types of job attributes typically included in studies of compensating differentials. As widely recognized, it is difficult to identify compensable working conditions, in part because heterogeneous worker preferences influence occupational choice (worker-job sorting), and because workers with high wages (for reasons that cannot be fully controlled) tend to sort into jobs with fewer disamenities (Hwang et al. 1992).

Using the merged CPS-O*NET database, we provide descriptive evidence comparing skill and working condition job attributes for registered nurses and college-educated workers economy-wide.

\footnotetext{
${ }^{14}$ Descriptions of factor analysis are provided in Gorsuch (1983) and Ingram and Neumann (2006).

${ }^{15}$ Although we prefer use of a single skill and single working conditions index, it is possible to include multiple indices. Using multiple-order factors and alternative rotations of factors, we obtain similar qualitative estimates of $\mathrm{RN}$ wage differentials. But there is some sensitivity in point estimates. For example, inclusion of a factor that heavily loads occupational attributes measuring caring for others increases estimates of relative RN wages since RNs rank high on this factor but such attributes are associated with lower pay, all else the same.

${ }^{16}$ Highly similar results are obtained if the indices are constructed using a weighted rather than simple average, using as weights the simple correlation between each job descriptor and occupational wages.
} 
Table 2 provides the means of the O*NET indices for the RN and the comparison group, shown jointly and separately by gender. As stated previously, our preferred skill index is SK1, the first principal factor constructed from $168 \mathrm{O}$ *NET job descriptors across the employment-weighted CPS/Census occupations. The economy-wide college workforce (i.e., those with associate, B.A. and M.A. degrees, excluding RNs) has a mean SK1 of .63, with equivalent values for women and men. The standard deviation is .81, below the 1.0 value produced by factor analysis when SK1 was constructed using economy-wide employment weights across occupations. Because the college group exhibits more concentrated employment across occupations, dispersion of the index values are lower. RNs exhibit a substantially higher skill index rating in $\mathrm{O}^{*} \mathrm{NET}$ than does the college control group, a 1.10 value that is more than a half standard deviation higher than the control group mean of .63.

Our preferred working conditions index, WC1, is the first principal factor using 38 working condition job descriptors. The college workforce has a mean WC1 value of -.48, -.65 among women and -.27 among men. The negative means for WC1 (and positive means for SK1) reflect the relatively high skills and good working conditions that characterize typical jobs for college-educated workers. The RN occupation receives a WC1 factor score of .29, nearly a full standard deviation above the college workforce mean. In short, O*NET evaluates RN jobs as requiring substantially higher skills and more demanding working conditions than does a typical job for college-educated workers.

An identical pattern is seen based on SK2 and WC2, the employment weighted averages of the reduced set of 135 skill and 19 working condition O*NET attributes. RNs have an SK2 value of 3.59, more than a half standard deviation higher than the 3.39 average across all college workers and jobs (3.33 for women and 3.44 for men). RNs have a WC2 value of 2.46, more than a standard deviation higher than the 1.81 average across all college workers and jobs (1.68 for women and 1.93 for men).

Space does not permit presenting values for all O*NET job attributes, but examples of skill attributes in which RNs are ranked particularly high or low are provided in tables 3a and 3b, along with the simple correlation of each attribute with wages. Ordering workers in the sample based on the values on each O*NET attribute, percentile rankings for RNs can be compiled. RNs rank near the $90^{\text {th }}$ percentile or higher for several skill measures. RNs rate particularly high on required abilities in problem sensitivity and inductive reasoning; on the skills of service orientation and social perspectives, on the work activities of identifying objects, actions, and events, and documenting/recording information; and on work context attributes measuring the consequence of error, frequency of decision making and importance of being exact or accurate. Many of these job attributes display a high correlation with wages. RNs also rank high in concern for others, assisting and caring for others, working with a work group or team, and adaptability/flexibility, although these attributes are weakly or negatively correlated with wages. 
RNs rank low in some attributes that are strong positive wage correlates, as seen in table 3b. These attributes include mathematical reasoning, management of financial resources, programming skills, scheduling work and activities, communicating with persons outside one's organization, interacting with computers, the level of competition, and use of e-mail. Given the nature of the RN job, these "low" ratings are not surprising.

Table 4 provides a comparison between RNs and the college control group for the 19 O*NET physical working conditions in the measure WC2. RNs rank in the $87^{\text {th }}$ percentile of the WC2 index. This high percentile ranking reflects not only demanding working conditions in the average RN job, but also the relatively low number of physical workplace disamenties in jobs populated by college-educated workers. Among the working conditions in which RNs rank high are exposure to radiation, disease, infection, hazardous conditions, and contaminants; physical proximity to others; cramped workspace or positions; and the wearing of protective or safety equipment. RNs rank low in exposure to the elements, working in vehicles or equipment, exposure to extreme temperatures; and exposure to high places.

The descriptive data from $\mathrm{O}^{*} \mathrm{NET}$ are revealing. They show that for a large number of workplace skills and abilities, nursing jobs are evaluated as requiring high levels. At the same time, nursing involves several demanding working conditions. ${ }^{17}$ Thus, some portion of the "high" RN wage is likely to result from skills and working conditions not reflected in typical wage analyses. We now turn to wages, first using standard analysis and then introducing the $\mathrm{O}^{*} \mathrm{NET}$ job attributes.

\section{Wage analysis using worker and location attributes}

In this section, we provide "CPS-only" regression analysis comparing hourly earnings among registered nurses and our control group of college-trained workers, with controls for standard individual and location characteristics. By these measures, RNs are paid well.

Lines 1 and 2 of table 5 provide the percentage difference in unadjusted mean wages and the difference in mean log wages, based on the values seen previously in table 1. Standard wage regression results are presented in line 3. ${ }^{18}$ The CPS-only log wage equations include potential experience (i.e., years since schooling completed) in quartic form, plus dummy variables for BA and MA degrees (versus associate degree), race/ethnicity (3 dummies for four groups), marital status (2), foreign-born (citizen and non-citizen), year (3) city size (6), and region (8). Inclusion of the regressors has little effect on the RN wage gap, the CPS-only gap being .220 log points, just .04 points higher than the .178 raw gap. Such

\footnotetext{
${ }^{17}$ In work not show, we compile descriptive evidence on $\mathrm{O}^{*} \mathrm{NET}$ "work value” descriptors not included in the wage analysis. The nursing occupation tends to satisfy the specific needs associated with workers who value social service, activity, co-workers, achievement, ability utilization, social status, and security. It is ranked low with respect to satisfying needs for recognition, independence, working conditions, and company policies and practices. ${ }^{18}$ Regression estimates are based on weighted least squares using CPS sample weights. Results are not sensitive to the use of weights.
} 
results suggest that the comparison group choice based on education is a reasonable one. Based on the standard log wage regression analysis shown in line 3, RNs are paid extremely well; even compared to a mix of college educated women and men. A “CPS-only” estimate of the RN wage advantage is much higher if an all-female comparison group is used, however, producing a gap of .348 as opposed to $.220{ }^{19}$

The question of how to treat gender is a difficult one. We want to compare RNs' actual wages to their long-run opportunity cost wages - what these individuals would have been earning in an alternative career path with similar costs of training and equally attractive working conditions. In some respects the average RN worker and job are most similar to male workers and jobs and in other respect to female workers and jobs. If the rationale for a gender-specific comparison is that women and men differ systematically in terms of preferences, job attributes, and accumulated work experience, then our inclusion of detailed occupational job attributes (seen in the next section) weakens the strength of such an argument, at least to the extent that $\mathrm{O}$ NET measures capture such differences. We believe comparing RNs to a mix of male and female wages/jobs (48\% women and $52 \%$ men) is reasonable. We continue to include results using the male- and female-only control groups, however, since not all readers need agree and such comparisons are informative in their own right.

\section{Relative nursing wages accounting for worker and job attributes}

Standard wage analyses using the CPS and other data sets are limited by the imperfect measurement of individual worker skills and the absence of direct information required job skills and working conditions. If compensable skills and working conditions required of RNs are substantially greater (less) for RNs than among measurably similar workers economy-wide, estimates of the RN wage gap are likely to be overstated (understated). In this section, we use the merged CPS/O*NET database to incorporate job attributes and worker characteristics into the wage analysis. ${ }^{20}$ Our approach is straightforward. We compare RN wage gaps from standard log wage regressions with and without control for the $\mathrm{O}^{*} \mathrm{NET}$ skill and working condition indices. In the next section, we provide matching estimates of percentage wage gaps that do not rely on the functional form of the wage equation.

Our preferred measures of workplace skills and working conditions are the principal factors SK1 and WC1 described previously. As seen in line 4 of table 5, addition of SK1 and WC1 to the CPS wage equation reduces the estimated $\mathrm{RN}$ wage gap by .14 log points, from .220 to .083 . This large reduction in the estimated wage gap primarily reflects the effect of the skill index. SK1 has a substantial effect on wages and the RN occupation has a high value of the skill index. The coefficient of .212 on SK1 implies

\footnotetext{
${ }^{19}$ Estimating a pooled equation with inclusion of a gender dummy produces a wage gap similar to that shown for women, since such an approach effectively compares $93 \%$ of the RN sample to women and only $7 \%$ to men.

${ }^{20}$ Because multiple workers are assigned common $\mathrm{O}$ NET values for each detailed occupation, we estimate and present standard errors "clustered" on occupation. Absent clustering, standard errors are roughly a tenth as large as those shown. Clustering does not change the coefficients.
} 
that a .47 difference in SK1 (the difference between the mean index value and value for RNs) is associated with wages of about .10 log points higher (inclusion of SK1 and WC1 change all the model's coefficients, making such calculations approximate).

Controlling for job working conditions and accurately estimating compensating differentials for disamenities is notoriously difficult (Hwang et al. 1992), estimates typically being biased downward. When we include the log of our index measure, WC1, of occupation-specific physical working conditions, we obtain a positive coefficient (but not significant) using the combined male-female sample, consistent with theory (the coefficients are negative and close to zero using the gender-specific control groups). The impact of working conditions based on the WC1 coefficient estimate of .024 and a RN-control group difference in mean WC1 of .77 is to lower the RN wage advantage by about .02 log points.

We also present results using the simple alternative indices of skills and working conditions. SK2 and WC2 include 135 and 19 O*NET job descriptors, respectively, a subset of the descriptors included in factor indices SK1 and WC1. Each of these indices represents the unweighted average value across the included variables and enters the wage regression in log form. Although these are crude indices as compared to those obtained through factor analysis, qualitative results are similar to those shown previously. Inclusion of $\ln S K 2$ and $\ln W C 2$ causes the RN wage differential to decline from .220 absent the job controls to .126, roughly half the CPS-only estimate. ${ }^{21}$ The difference between this estimate and the .083 estimate using the principal factor indices is largely driven by the ('wrong') negative but insignificant sign on the working conditions index, increasing the RN gap estimate despite more difficult working conditions for RNs than for the comparison group.

Table 5 also shows results using gender-specific comparison groups. With an all-male control group, the RN wage gap using indices SK1 and WC1 is effectively zero (.008). Compared to women, however, the RN gap is substantial (.257). Although such estimates are informative, we focus on the "gender-blind” wage gap estimate (i.e., .083) given the presence of detailed job attribute controls. What is clear from our analysis to this point is that skill attributes are strongly related to wages across the labor market, the RN job is evaluated as possessing a high level of skills, and estimated RN wage gaps are sharply reduced following control for job skills.

\section{Do logarithmic wage gaps overstate relative nursing wages?}

A final consideration, and an important one, is whether the log wage gap measure from the Mincerian wage equation is appropriate in this particular application. Evident from the descriptive statistics is a large difference in wage gaps between RNs and the comparison group based on then percentage differences in mean dollars versus the differences in mean logs converted to a percentage.

\footnotetext{
${ }^{21}$ The coefficients can be interpreted as elasticities measuring the percentage effect on wages from a percentage
} change in the skill or working conditions index. 
The raw log wage difference between RNs and the comparison group is .178 log points, which translates into an approximate percentage differential of $19.5 \%$. In sharp contrast, the percentage difference in mean dollar wages, $\left(\overline{W_{R N}}-\overline{W_{C}}\right) / \overline{W_{C}}$, is only $7.4 \%$. A compressed right tail of the RN wage distribution as compared to the comparison group (as seen in Figures 2a and 2b) causes the log wage gap to provide a poor approximation of the RN percentage wage gap.

Although the Mincerian semilog wage equation remains the standard approach for estimating percentage wage gaps in labor economics, Blackburn (2007) has shown that it is not appropriate in all applications (see related work by Manning 1998; Manning and Mullahy 2001). The Mincerian wage equation model is:

$$
W=e^{x \beta} u
$$

If $u$ is homoskedastic then the model can be written and estimated in its standard semilog form:

$$
\ln W=x \beta+u
$$

The semilog model provides consistent estimates of $\beta$ only under the assumption that the distribution of the error term is independent of the regressors. However, the assumption of homoskedasticity is violated in our case since the error distribution is correlated with the RN indicator variable.

Our approach to the log gap issue is to examine RN wage gaps obtained from a propensity score matching model that does not rely on the functional form of the wage equation. The matching approach addresses two concerns. First, for each RN it provides a matched non-RN with similar attributes (i.e., a similar conditional propensity to be a nurse). This allows us to check if RN regression gap estimates are sensitive to the data support and implicit weighting of the control group. Second, the matching RN wage gaps estimate are nonparametric, constructed from straightforward mean wage differences in dollars or logs between RNs and the matched comparison group. Thus, we need not rely on the log transformation to estimate the percentage gap. A comparison of the Mincerian log gap with the matching estimate of the percentage gap shows whether or not the semilog specification provides a reliable estimate of the percentage gap.

The propensity score matching differentials are estimated as follows. First a logit model is estimated for the full sample (both RNs and non-RNs) on the likelihood of being an RN, conditional on the explanatory variables previously included in the wage equation. First-step models are estimated with and without inclusion of the $\mathrm{O}^{*}$ NET variables. All workers are then ordered from low to high based on their likelihood of being an RN (the propensity score) and divided into deciles (10 groups). ${ }^{22}$ Each RN is then matched randomly (with replacement) to a non-RN within the same decile. The "log percentage"

\footnotetext{
${ }^{22}$ Quintiles are typically used for matching estimators. Because our control group is extremely large and has a strong overlap with the RN distribution over the data support, we are able to use a finer breakdown to improve the "quality" of the matches (i.e., closer propensity scores).
} 
and "dollar percentage” RN wage gaps for this same set of matches are then calculated in straightforward fashion. We conduct and compile 100 sets of these matches. We report the means and standard deviations of both the percentage and the mean log $\mathrm{RN}$ wage gaps across these 100 rounds.

Line 1 of table 6 repeats the previously reported log wage gaps from our regression analysis, coupled with the percentage differentials implied by these gaps. Line 2 reports the corresponding RN log wage gaps compiled from the matching estimator. Differences between lines 1 and 2 stem largely from moving from a regression weighted data support to a nonparametric matching estimator in which the control group support "mimics" the attributes of the "treatment” nurse sample. The estimated log gaps from matching (line 2) are highly similar to the regression estimates (line 1). As shown previously, the standard wage regression estimate of the RN log gap is .220 and that with the O*NET skill and working condition indices is .083. The corresponding matching estimators are .234 and .066, within .02 log points of the regression estimates. The similarity in estimates indicates that the regressions provide a weighted control group support similar to the support from explicit matching. The use of an OLS regression versus matching does not by itself produce meaningful differences in RN log gap estimates.

Line 3 provides the percentage differential estimate from the matching model, calculated directly by $\left(\overline{W_{R N}}-\overline{W_{C}}\right) / \overline{W_{C}}$ rather than approximated by conversion from the log gap. The differences are substantial. In contrast to the $26.5 \%$ log wage gap matching estimate (without O*NET), the corresponding arithmetic percentage calculated from the same matched individuals is $15.0 \%$. With inclusion of $\mathrm{O} * \mathrm{NET}$, the RN log wage gap from the matching estimator is $6.9 \%$, but the arithmetic percentage calculated directly from the same matched sample is $-4.0 \%{ }^{23}$ In short, use of the standard log wage gap estimator for RNs causes wage gaps to be overstated by about 11 percentage points. Nursing wages appear roughly equivalent to long-run opportunity costs.

Although the gender-blind results are our preferred estimates, table 6 also shows matching estimates using female- and male-only control groups. Using the female control group (line 4), the match estimates are considerably higher than the gender-blind approach, 35.4\% and 18.1\% based on propensity score models excluding and including the $\mathrm{O}^{*}$ NET skill and working condition indices. As expected, estimates are substantially lower using an all-male comparison group (line 5).

\section{Other issues: Benefits and shift work}

This study focuses on earnings differences between RNs and similar workers and jobs. A more complete analysis would account for nonwage benefits and focus on total compensation. Unfortunately, household data providing information on worker attributes do not generally report the dollar costs of

\footnotetext{
${ }^{23}$ The decline in the percentage gap from $15.0 \%$ to $-4.0 \%$ is due to a $\$ 5.04$ increase in the matched control group wage across the 100 rounds (the RN mean wage remains the same) resulting from adding the O*NET skill and working condition indices to the logit models that generate the propensity scores and thus affect resulting matches.
} 
benefits, while surveys providing information on benefit costs do not report worker and location characteristics. Hence, multivariate analysis of RN benefits relative to a control group is not possible.

Published data on employer benefit costs for RNs, however, suggest that benefits for RNs are no larger than for workers economy-wide. The Employer Costs for Employee Compensation (U.S. BLS 2008a) provides data on total compensation, dividing it between wages and salaries versus benefits, the latter including a comprehensive set of voluntary and mandated benefits (mandatory being Social Security, Medicare, UI, etc.). In June 2008, benefits as a percent of total hourly compensation among private sector RNs (table 27, p. 285) measure 25.9\% - \$11.50 in benefits, \$32.90 in wages and salaries, and $\$ 44.40$ in compensation. For all full-time private sector workers the corresponding figure is $27.2 \%$ of compensation - \$8.26 in benefits, \$22.16 in wages and salaries, and \$30.42 in compensation (table 19, p. 224 - a full-time/part-time breakdown is not provided for private and public workers combined). ${ }^{24}$ Based on these figures, it is fair to conclude that benefits as a percent of total compensation is no greater, and probably somewhat lower, for RNs than for comparable workers and jobs economy-wide. Hence, estimates of the RN wage gap do not understate the differential in compensation.

An issue not formally addressed in this paper is the difference in timing of work. Healthcare workers are more likely to work weekends and non-standard shifts. A recent BLS newsletter (U.S. BLS 2008b) reports that healthcare workers are more likely to work on weekends and holidays than are workers economy-wide. Using information from the 2003-2007 American Time Use Surveys they report that on a given weekday, $80 \%$ of full-time healthcare practitioner and technical workers (a category that includes RNs) are working, compared to $88.1 \%$ of workers in non-health occupations. On holidays and weekends, $35.1 \%$ of the health employees as compared to $31.2 \%$ of non-health employees are working.

Failure to account for timing of work will cause the RN wage differential to be overstated. Of course, it is difficult "price” differentials associated with time of work since the choice to work particular days or shifts is affected by selection (e.g., Kostiuk 1990). We can construct a rough back-of-theenvelope estimate. Schumacher and Hirsch (1997) examine differences in earnings for RNs associated with shift work. Based on the May 1985 and 1991 CPS Dual Job Supplements, they find that 57\% of RNs work day shifts, with the others split between night, evening, rotating or split shift, and other shifts. Relative to a day shift, they estimate compensating differentials for night work of 11 percent and for the other shifts about 4 percent. Assume that such scheduling and shift differentials for RNs hold today. Published information from the May 2004 CPS supplement on flexible and shift schedules provides recent data for full-time workers economy-wide. As compared to the $57 \%$ of RNs who have day schedules, the economy-wide the figure is $85 \%$. Based on the differences between RNs and workers

\footnotetext{
${ }^{24}$ The ECEC includes supplemental pay (e.g., overtime and shift pay) as benefits. The figures shown in the text subtract supplemental pay from benefits and add them to wages and salary. Absent the shift of supplemental pay, benefits as a percentage of total compensation are $29.5 \%$ for RNs and $30.5 \%$ for full-time private sector workers.
} 
economy-wide for each shift category, coupled with the wage differentials estimates by Hirsch and Schumacher, we calculate that the RN wage differential would be .018 log points lower if adjusted for shift work. ${ }^{25}$ Although this is a rough estimate, it reinforces our conclusion that relative pay among nurses is overstated by standard wage regression analysis and is likely to be close to opportunity costs.

\section{Interpretation and conclusions: Is the shortage puzzle resolved?}

Our analysis has at least three important implications. Most important, the results imply that wage differences between RNs and similar workers economy-wide are substantially smaller than implied by standard log wage estimates. Three principal reasons lead to this conclusion. First, the RN job requires unusually high skills as compared to typical jobs populated by workers with similar levels of schooling, skills not fully reflected in standard CPS variables. Likewise, the RN job involves more difficult working conditions than do most jobs filled by college-educated workers. Controlling for occupation skills and working conditions sharply reduces estimates of an RN wage advantage. Second, comparing nursing wages to a combined male and female control group lowers estimates of the RN wage gap compared to estimates conditioning on gender or using female-only control groups. And third, Mincerian log wage gaps substantially overstate percentage wage gaps among nurses. Using an arguably more appropriate nonparametric matching estimator, the RN percentage differential is close to zero.

A second and more general implication is that wage analyses can be enriched by supplementing standard worker characteristics and location measures with job-based measures of compensable skills and working conditions. The $\mathrm{O}^{*} \mathrm{NET}$ database provides an unusually rich set of occupation-based measures.

A third implication is that Mincerian log wage gap estimates should be questioned not just in the case of nurses, but whenever one compares a single occupation or "narrow" treatment group to a (generally appropriate) broad comparison group. There is no shortage of such examples in the labor economics literature.

Prior studies have found that registered nurses receive substantially higher pay than other collegeeducated women. We obtain similar results using the standard approach. A large RN wage premium would be puzzling and difficult to explain if nursing markets are close to competitive. Large premiums are even more difficult to explain with a monopsony model, which predicts that profit maximizing employers pay wages below opportunity costs, even those such wages result in shortages (profits would fall were wages to increase). Our analysis goes a long way toward resolving this apparent puzzle. We conclude that RNs are paid wages relatively close to rather than well above long-run opportunity costs that is, wages close to what would have been received in an alternative career in jobs with similar skills and working conditions.

\footnotetext{
${ }^{25}$ The details of this calculation are available on request.
} 
The conclusion that RNs are paid close to opportunity costs reduces but does not eliminate the puzzle of shortages. How does one explain high vacancy rates and shortages if RN wage rates are paid, on average, at (or above) opportunity costs? We rule out monopsony as the principal explanation, given that long-run wages are close to opportunity costs, RNs demonstrate high mobility across multiple employers, and because there is little direct evidence supporting the monopsony explanation (e.g., Hirsch and Schumacher 2005; Matsudaira 2008).

A more convincing explanation for shortages, although not one we analyze formally, involves two factors, one on the demand side and the other the supply side. First, over time there has been rising demand for nurses combined with hospital budgets that adjust with a lag. Second, entry into the nursing profession is constrained, with available training slots below the number of qualified applicants. Constraints on nursing program enrollments stem from several sources, but key factors are the limited growth in nursing education opportunities (relative to demand) and the difficulty in hiring qualified nursing faculty at salary levels funded by educational institutions (e.g., Aiken 2008; Rahn and Wartman 2007, Spetz and Given 2003). The American Association of Colleges of Nursing (2007) reports increasing enrollments in recent years (at a declining rate), but record numbers of qualified applicants turned away, 29.4, 37.5, and 38.4 thousand in 2005, 2006, and 2007. This compares to 51.2 thousand B.A. nursing degrees conferred in the 2005-06 academic year, the most recent year available (Snyder, Dillow, and Hoffman, 2008, table 265). A shortage of nursing faculty is the primary reason cited for rejecting applicants. ${ }^{26}$

A final point is that modest deviations of nursing wages from long-run opportunity costs cannot be ruled out a priori. On the one hand, funding constraints among employers combined with imperfect mobility can lead to "underpaid” nurses, although there is little evidence suggesting systematic underpayment. On the other hand, institutional constraints on nurse training can lead to shortages coexisting with wages above long run opportunity costs, with “short-run” RN wages exceeding pay among similar non-nursing workers and jobs. The supply constraint in training might best explain wage advantages seen for RNs compared to other college-educated workers. The size of any wage advantage, however, is not nearly as large as standard analysis suggests. Our evidence shows that RNs are neither substantially “underpaid' nor “overpaid.” We cannot rule out that RNs, on average, are paid about "right” - close to long-run opportunity costs.

\footnotetext{
${ }^{26}$ An additional supply explanation for which there is some evidence is that labor supply among nurses (particularly married women) is countercyclical, accentuating shortage problems during high demand periods (Buerhaus 1993; Buerhaus, Staiger, and Auerbach 2003).
} 


\section{References}

Aiken, L.H., Cheung, R., 2008. "Nurse workforce challenges in the United States: Implications for policy,” OECD Health Working Papers, No. 35.

American Association of Colleges of Nursing, 2007. "Enrollment Growth Slows at U.S. Nursing Colleges and Universities in 2007 Despite Calls for More Registered Nurses,” News Release, December 3. Accessed at < http://www.aacn.nche.edu/Media/NewsReleases/2007/enrl.htm $>$ on October 19, 2008.

Bhaskar, V., Manning, A., To, T., 2002. “Oligopsony and monopsonistic competition in labor markets.” Journal of Economic Perspectives 16:2, 155-174.

Boal, W.M., Ransom, M.R., 1997. "Monopsony in the labor market.” Journal of Economic Literature 35:1, 86-112.

Blackburn, M. L., 2007. “Estimating wage differentials without logarithms.” Labour Economics 14:1, 73-98.

Bollinger, C.R., Hirsch, B.T., 2006. "Match bias from earnings imputation in the Current Population Survey: The case of imperfect matching.” Journal of Labor Economics 24:3, 483-519.

Buerhaus, P.I., 1993. "Effects of RN wages and non-wage income on the performance of the hospital RN labor market,” Nursing Economics 11:3, 129-135.

Buerhaus, P.I., Staiger, D.O., Auerbach, D.I., 2003. "Is the current shortage of hospital nurses ending?” Health Affairs 22:6, 191-198.

Currie J., Farsi, M., MacLeod, W.B. 2005. "Cut to the Bone? Hospital Takeovers and Nurse Employment Contracts," Industrial and Labor Relations Review, 58:3, 471-493.

Folland, S., Goodman, A.C., M. Stano, 2007. The Economics of Health and Health Care, $5^{\text {th }}$ edition. Pearson Prentice Hall, Upper Saddle River, NJ.

Gorsuch, R.L., 1983. Factor Analysis, $2^{\text {nd }}$ edition. Lawrence Erlbaum: Hillsdale, NJ.

Hirsch B.T., Schumacher, E.J., 2004. "Match bias in wage gap estimates due to earnings imputation.” Journal of Labor Economics 22:3, 689-722. , 2005. "Classic monopsony or new monopsony? Searching for evidence in nursing labor markets.” Journal of Health Economics 24:5, 969-989.

Hwang, H., Reed, W.R., Hubbard, C., 1992. “Compensating wage differentials and unobserved productivity.” Journal of Political Economy 100:4, 835-858.

Ingram, B.F, Neumann, G.R., 2006. “The returns to skill.” Labour Economics13:1, 35-59.

Kennedy, P.E. 1981. "Estimation with Correctly Interpreted Dummy Variables in Semilogarithmic Equations.” American Economic Review 71:4, 801.

Kostiuk, P.F., 1990. “Compensating differentials for shift work.” Journal of Political Economy 98:5, 1054-75.

Manning, A., 2003. Monopsony in Motion: Imperfect Competition in Labor Markets. Princeton University Press, Princeton, NJ.

Manning, W.G., 1998. "The logged dependent variable, heteroscedasticity, and the retransformation problem.” Journal of Health Economics 17, 283-295.

Manning, W.G., Mullahy, J., 2001. “Estimating log models: to transform or not to transform?” Journal of Health Economics 20, 461-494. 
Matsudaira, J.D., 2008.“Monopsony in the labor market for nurses.” ASHE Meetings, Durham, NC, June.

National Center for Health Workforce Analysis, Bureau of Health Professions, USDHHS, 2002. Projected Supply, Demand, and Shortages of Registered Nurses: 2000-2020. Rockville, MD.

Rahn, D.W., Wartman, S.A., 2007. "For the health-care work force, a critical prognosis.” The Chronicle Review 54:10, B14.

Schumacher, E.J., Hirsch, B.T., 1997. "Compensating differentials and unmeasured ability in the labor market for nurses: Why do hospitals pay more?” Industrial and Labor Relations Review 50:4, 557-579.

Snyder, T.D., Dillow, S.A., Hoffman, C.M., 2008. Digest of Education Statistics 2007 (NCES 2008022). National Center for Education Statistics, U.S. Department of Education.

Spetz, J., Given, R., 2003. "The future of the nurse shortage: Will wage increases close the gap?” Health Affairs 22:6, 199-206.

Staiger, D., Spetz, J., Phibbs, C., 1999. "Is there monopsony in the labor market? Evidence from a natural experiment.” National Bureau of Economic Research working paper no.7258, July.

Sullivan, D., 1989. "Monopsony power in the market for nurses.” Journal of Law and Economics 32:2, pt. 2, S135-178.

U.S. Department of Labor, Bureau of Labor Statistics, 2008a. "Employer Costs for Employee Compensation, Historical Listing, March 2004-June 2008,” September 10. Accessed September 15, 2008 at <ftp://ftp.bls.gov/pub/special.requests/ocwc/ect/ececqrtn.pdf>

U.S. Department of Labor, Bureau of Labor Statistics, 2008b. "Workdays for People in Healthcare Occupations,” Issues in Labor Statistics, Summary 08-07/September. 
Figure 1

Monopsony in the Labor Market

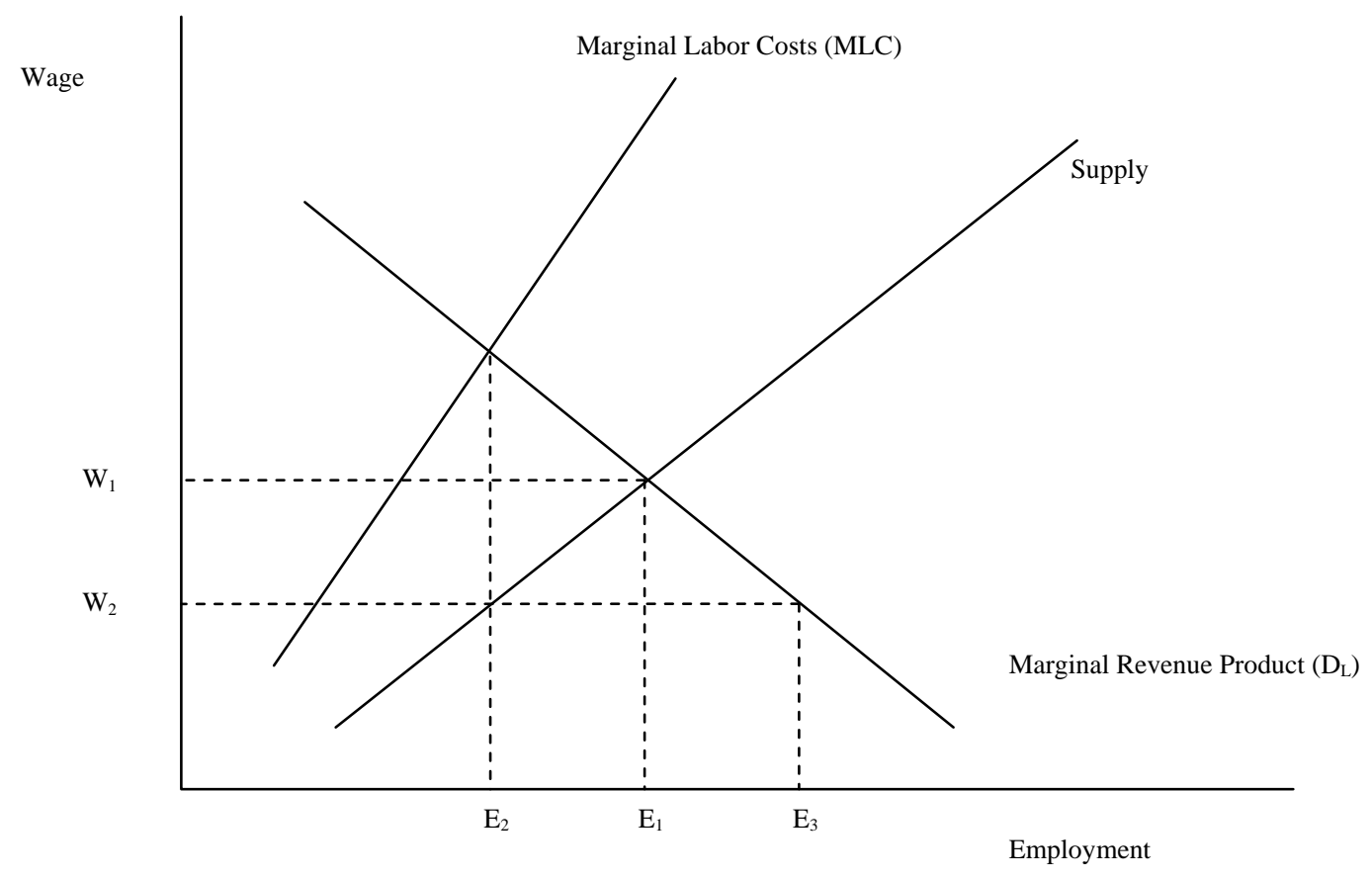


Figure 2a: Wage Distributions for RNs and the College Comparison Group

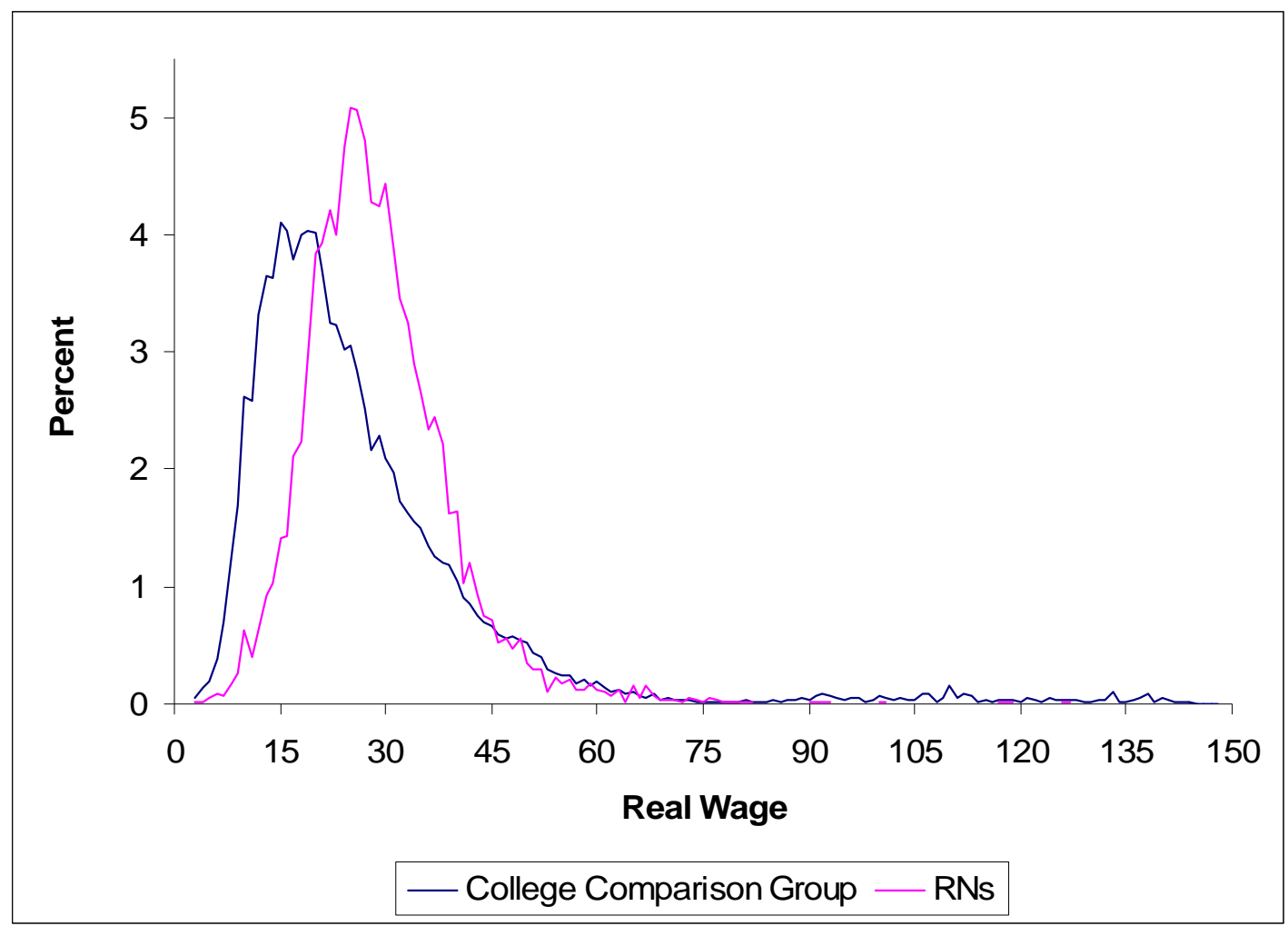

Figure 2b: Upper Tail of the RN and Comparison Group Wage Distributions

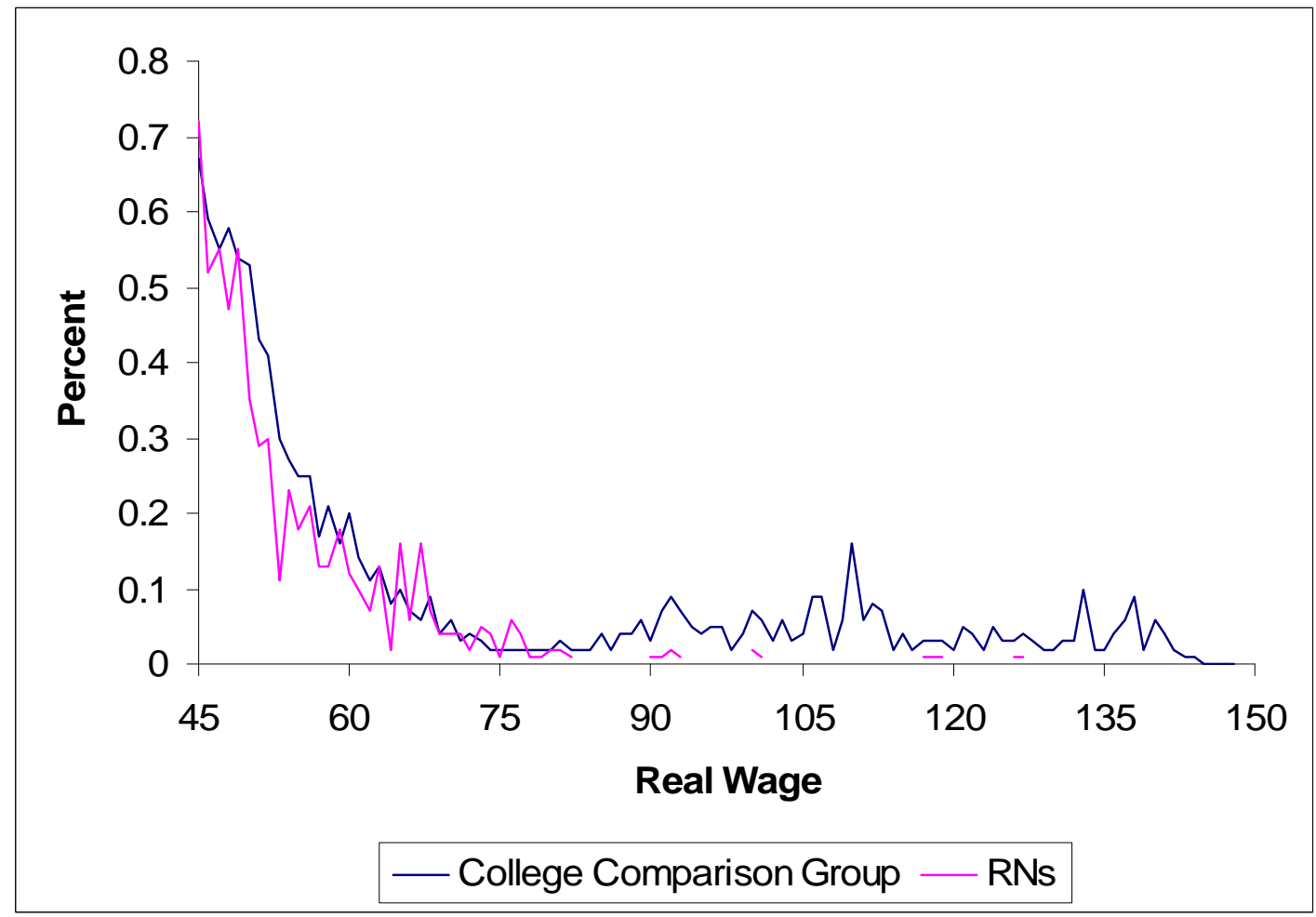


Table 1

Wages among RNs and the Comparison Group, With and Without Imputed Earners

\begin{tabular}{|c|c|c|c|c|}
\hline & RNs & $\begin{array}{l}\text { College } \\
\text { Control } \\
\text { Group }\end{array}$ & Women & Men \\
\hline \multicolumn{5}{|l|}{$\begin{array}{l}\text { Absent imputed } \\
\text { earners }\end{array}$} \\
\hline Real wage & $\begin{array}{l}29.45 \\
(11.62)\end{array}$ & $\begin{array}{l}27.43 \\
(19.40)\end{array}$ & $\begin{array}{l}23.18 \\
(14.11)\end{array}$ & $\begin{array}{l}31.11 \\
(22.38)\end{array}$ \\
\hline Log wage & $\begin{array}{l}3.3144 \\
(.3716)\end{array}$ & $\begin{array}{l}3.1362 \\
(.5717)\end{array}$ & $\begin{array}{l}3.0081 \\
(.5054)\end{array}$ & $\begin{array}{l}3.2539 \\
(.5852)\end{array}$ \\
\hline Sample size & 8,292 & 135,593 & 64,565 & 71,028 \\
\hline \multicolumn{5}{|l|}{$\begin{array}{l}\text { Including imputed } \\
\text { earners }\end{array}$} \\
\hline Real wage & $\begin{array}{l}28.21 \\
(12.96)\end{array}$ & $\begin{array}{l}27.37 \\
(19.58)\end{array}$ & $\begin{array}{l}23.34 \\
(13.97)\end{array}$ & $\begin{array}{l}30.98 \\
(22.49)\end{array}$ \\
\hline Log wage & $\begin{array}{l}3.2456 \\
(.4413)\end{array}$ & $\begin{array}{l}3.1323 \\
(.5727)\end{array}$ & $\begin{array}{l}3.0018 \\
(.5168)\end{array}$ & $\begin{array}{l}3.2447 \\
(.5944)\end{array}$ \\
\hline Sample size & 11,514 & 190,119 & 90,082 & 100,037 \\
\hline Nonresponse rate & $28.0 \%$ & $28.7 \%$ & $28.3 \%$ & $29.0 \%$ \\
\hline
\end{tabular}

Shown are weighted means (using CPS sample weights), with standard deviations in parentheses. RN includes only those with at least an associate degree and no greater than a master's degree. The sample excluding imputed earners is used in all subsequent empirical work. Not shown in the table are means for the imputed sample. The mean imputed dollar wage for nonrespondent RNs is \$25.30 and mean imputed log wage is 3.0849 . 
Table 2

O*NET Skill and Working Condition Indices: Means by Group

\begin{tabular}{|l|l|l|l|l|}
\hline & RNs & $\begin{array}{l}\text { College } \\
\text { Comparison } \\
\text { Group }\end{array}$ & Women & Men \\
\hline SK1 & 1.10 & 0.63 & 0.63 & 0.63 \\
$(0.81)$ & $(0.77)$ & $(0.84)$ \\
\hline WC1 & 0.29 & -0.48 & -0.65 & -0.27 \\
& & $(0.81)$ & $(.53)$ & $(0.96)$ \\
\hline SK2 & 3.59 & $\begin{array}{l}3.39 \\
(0.40)\end{array}$ & $\begin{array}{l}3.33 \\
(0.39)\end{array}$ & $\begin{array}{l}3.44 \\
(0.40)\end{array}$ \\
\hline WC2 & 2.46 & $\begin{array}{l}1.81 \\
(0.48)\end{array}$ & $\begin{array}{l}1.68 \\
(0.31)\end{array}$ & $\begin{array}{l}1.93 \\
(0.56)\end{array}$ \\
\hline Sample Size & 8,292 & 135,593 & 64,565 & 71,028 \\
\hline
\end{tabular}

Shown are weighted means (using CPS sample weights), with standard deviations in parentheses. All RNs are assigned uniform O*NET attribute values. 
Table 3a

O*NET Skill Attributes where RNs Rate High: Percentile Rank and Wage Correlations

\begin{tabular}{ccc}
\hline \multicolumn{1}{c}{ Description } & $\begin{array}{c}\text { RN } \\
\text { Rank }\end{array}$ & $\begin{array}{c}\text { Simple Wage } \\
\text { Correlation }\end{array}$ \\
\hline Abilities -- Enduring attributes of the individual that influence performance & & \\
Problem Sensitivity & 96 & 0.32 \\
Inductive Reasoning & 93 & 0.37 \\
Oral Comprehension & 85 & 0.38 \\
Deductive Reasoning & 78 & 0.42
\end{tabular}

Skills -- Developed capacities that facilitate learning, the more rapid acquisition of knowledge, or performance of activities that occur across jobs

Service Orientation

92

0.21

Social Perceptiveness

90

0.17

Science

88

0.27

Critical Thinking

87

0.37

Work Activities - Types of job behaviors occurring on multiple jobs

Assisting and Caring for Others

$-0.01$

Identifying Objects, Actions, and Events

Documenting/Recording Information

Monitor Processes, Materials, or Surroundings

0.20

Updating and Using Relevant Knowledge

0.34

Performing for or Working Directly with the Public

Work Context - Physical and social factors that influence the nature of work

Consequence of Error $\quad 96$

Work With Work Group or Team

Responsible for Others' Health and Safety

Frequency of Decision Making

Importance of Being Exact or Accurate

Work Style -- Personal characteristics that can affect how well someone performs a job

Concern for Others

$-0.08$

Self Control

Adaptability/Flexibility

0.12

Cooperation

Dependability

Integrity

Independence

0.16

Attention to Detail

0.15

Stress Tolerance 
Table 3b

O*NET Skill Attributes where RNs Rate Low: Percentile Rank and Wage Correlations

\begin{tabular}{|c|c|c|}
\hline Description & $\begin{array}{l}\text { RN } \\
\text { Rank }\end{array}$ & $\begin{array}{l}\text { Simple } \\
\text { Wage } \\
\text { Correlation }\end{array}$ \\
\hline \multicolumn{3}{|c|}{ Abilities -- Enduring attributes of the individual that influence performance } \\
\hline Mathematical Reasoning & 6 & 0.27 \\
\hline Visualization & 7 & 0.12 \\
\hline Number Facility & 8 & 0.19 \\
\hline Fluency of Ideas & 30 & 0.33 \\
\hline Originality & 30 & 0.33 \\
\hline \multicolumn{3}{|c|}{$\begin{array}{l}\text { Skills -- Developed capacities that facilitate learning, the more rapid acquisition of knowledge, or performance } \\
\text { of activities that occur across jobs }\end{array}$} \\
\hline Management of Financial Resources & 10 & 0.25 \\
\hline Installation & 16 & 0.19 \\
\hline Programming & 17 & 0.25 \\
\hline Management of Material Resources & 21 & 0.26 \\
\hline \multicolumn{3}{|c|}{ Work Activities - Types of job behaviors occurring on multiple jobs } \\
\hline Scheduling Work and Activities & 19 & 0.23 \\
\hline Communicating with Persons Outside Organization & 21 & 0.26 \\
\hline Interacting With Computers & 23 & 0.27 \\
\hline Thinking Creatively & 26 & 0.26 \\
\hline Performing Administrative Activities & 26 & 0.15 \\
\hline \multicolumn{3}{|c|}{ Work Context - Physical and social factors that influence the nature of work } \\
\hline Degree of Automation & 18 & 0.07 \\
\hline Electronic Mail & 26 & 0.31 \\
\hline Level of Competition & 29 & 0.24 \\
\hline Public Speaking & 31 & 0.08 \\
\hline \multicolumn{3}{|c|}{ Work Style -- Personal characteristics that can affect how well someone performs a job ${ }^{*}$} \\
\hline Persistence & 61 & 0.22 \\
\hline Leadership & 62 & 0.17 \\
\hline Innovation & 68 & 0.20 \\
\hline
\end{tabular}

${ }^{*}$ RNs were in the $61^{\text {st }}$ or above percentile for all attributes in this group. 
Table 4

RN Percentile Rankings of Working Condition Index WC2 and Its Component Attributes

\begin{tabular}{|c|c|}
\hline Description & $\begin{array}{l}\text { RN } \\
\text { Rank }\end{array}$ \\
\hline Working Condition Index (WC2) & 87 \\
\hline Physical Proximity to Others & 95 \\
\hline Exposed to Radiation & 95 \\
\hline Exposed to Disease or Infections & 95 \\
\hline Wear Specialized Protective or Safety Equipment & 93 \\
\hline Cramped Work Space, Awkward Positions & 93 \\
\hline Wear Common Protective or Safety Equipment & 91 \\
\hline Exposed to Hazardous Conditions & 88 \\
\hline Exposed to Contaminants & 88 \\
\hline Sounds, Noise Distracting or Uncomfortable & 83 \\
\hline Exposed to Minor Burns, Cuts, Bites, or Stings & 83 \\
\hline Extremely Bright or Inadequate Lighting & 81 \\
\hline Exposed to Whole Body Vibration & 70 \\
\hline Exposed to Hazardous Equipment & 60 \\
\hline Outdoors, Under Cover & 47 \\
\hline In an Enclosed Vehicle or Equipment & 37 \\
\hline Very Hot or Cold Temperatures & 32 \\
\hline Exposed to High Places & 32 \\
\hline Outdoors, Exposed to Weather & 23 \\
\hline In an Open Vehicle or Equipment & 11 \\
\hline
\end{tabular}


Table 5

RN Wage Differentials with the College Comparison Group, Jointly and by Gender

\begin{tabular}{|c|c|c|c|c|c|c|c|c|c|}
\hline & \multicolumn{3}{|c|}{ College Comparison Group } & \multicolumn{3}{|c|}{ Female Only } & \multicolumn{3}{|c|}{ Male Only } \\
\hline & $\begin{array}{c}\text { RN } \\
\text { Wage } \\
\text { Gap }\end{array}$ & $\begin{array}{c}\text { Skill } \\
\text { Coefficient }\end{array}$ & $\begin{array}{c}\text { WC } \\
\text { Coefficient }\end{array}$ & $\begin{array}{l}\text { RN Wage } \\
\text { Gap }\end{array}$ & $\begin{array}{c}\text { Skill } \\
\text { Coefficient }\end{array}$ & $\begin{array}{c}\text { WC } \\
\text { Coefficient }\end{array}$ & $\begin{array}{l}\text { RN Wage } \\
\text { Gap }\end{array}$ & $\begin{array}{c}\text { Skill } \\
\text { Coefficient }\end{array}$ & $\begin{array}{c}\text { WC } \\
\text { Coefficient }\end{array}$ \\
\hline $\begin{array}{l}\text { 1. Percent wage } \\
\text { difference }\end{array}$ & 0.074 & -- & -- & 0.271 & -- & -- & -0.053 & -- & -- \\
\hline $\begin{array}{l}\text { 2. Unadjusted log } \\
\text { wage differential }\end{array}$ & 0.178 & -- & -- & 0.306 & -- & -- & 0.060 & -- & -- \\
\hline $\begin{array}{l}\text { 3. CPS-only log } \\
\text { differential }\end{array}$ & $\begin{array}{l}0.220 \\
(.025)\end{array}$ & -- & -- & $\begin{array}{c}.348 \\
(.022)\end{array}$ & -- & -- & $\begin{array}{c}.115 \\
(.025)\end{array}$ & -- & -- \\
\hline $\begin{array}{l}\text { 4. CPS plus SK1 } \\
\text { and WC1 }\end{array}$ & $\begin{array}{l}0.083 \\
(.034) \\
\end{array}$ & $\begin{array}{c}.212 \\
(.026) \\
\end{array}$ & $\begin{array}{c}.024 \\
(.016) \\
\end{array}$ & $\begin{array}{c}.257 \\
(.042) \\
\end{array}$ & $\begin{array}{c}.197 \\
(.022)\end{array}$ & $\begin{array}{l}-.019 \\
(.024)\end{array}$ & $\begin{array}{c}.008 \\
(.029)\end{array}$ & $\begin{array}{c}.198 \\
(.026)\end{array}$ & $\begin{array}{l}-.020 \\
(.014)\end{array}$ \\
\hline $\begin{array}{l}\text { 5. CPS plus lnSK2 } \\
\text { and lnWC2 }\end{array}$ & $\begin{array}{l}0.126 \\
(.023)\end{array}$ & $\begin{array}{l}1.411 \\
(.140)\end{array}$ & $\begin{array}{l}-.051 \\
(.051)\end{array}$ & $\begin{array}{l}0.267 \\
(.033)\end{array}$ & $\begin{array}{l}1.301 \\
(.111)\end{array}$ & $\begin{array}{l}-0.108 \\
(.066)\end{array}$ & $\begin{array}{c}.078 \\
(.021)\end{array}$ & $\begin{array}{l}1.314 \\
(.150)\end{array}$ & $\begin{array}{l}-.192 \\
(.045)\end{array}$ \\
\hline
\end{tabular}

Shown are wage differences comparing RNs to pooled, female, and male college-educated comparison groups. Row 1 shows the percent difference in the average real wage using the comparison group as the base. Row 2 shows the unadjusted log wage differential. Row 3 shows the coefficient on a dummy variable from a log wage regression that includes controls for potential experience (i.e., years since schooling completed) in quartic form, plus dummy variables for BA and MA degrees (versus associate degree), race/ethnicity (3 dummies for four groups), marital status (2), foreign-born (citizen and non-citizen), year (3) city size (6), and region (8).

Row 4 adds SK1 and WC1 to the regression and row 5 the log of SK2 and WC2. Rows 4 and 5 display coefficients on the skill and working condition indices described in the text. Means in rows 1-2 and regression results in rows 3-5 apply CPS sample weights. Standard errors, clustered on occupation, are shown in parentheses. 
Table 6

Propensity Score Matching Results

\begin{tabular}{|l|c|c|}
\hline & CPS Only & $\begin{array}{c}\text { CPS Plus O*NET } \\
\text { SK1 and WC1 }\end{array}$ \\
\hline 1. Regression log gaps and implied percentage & $\begin{array}{c}.220 / 24.6 \% \\
(.025)\end{array}$ & $\begin{array}{c}.083 / 8.7 \% \\
(.034)\end{array}$ \\
\hline 2. Matching log gaps and implied percentage & $.234 / 26.4 \%$ & $.066 / 6.8 \%$ \\
{$[.007]$} & {$[.008]$} \\
\hline 3. Matching dollar \% gaps: gender blind & $15.0 \%$ & $-4.0 \%$ \\
& {$[.90]$} & {$[1.24]$} \\
\hline 4. Matching dollar \% gaps: female controls & $35.4 \%$ & $18.1 \%$ \\
& {$[.74]$} & {$[1.47]$} \\
\hline 5. Matching dollar \% gaps: male controls & $2.3 \%$ & $-10.5 \%$ \\
& {$[.94]$} & {$[1.21]$} \\
\hline
\end{tabular}

Line 1 regression estimates and clustered standard errors shown previously in table 5 . In lines 1 and 2, estimated log gaps and implied percentage gaps are shown. Matching estimates in lines 2-5 are based on 100 imputation rounds and random matching within deciles. Standard deviations across the 100 rounds are shown in brackets. 